alternative), "Eye Surgeon" is self-explanatory and further, it suggests the use of surgery in the treatment of eye diseases. Compare the simplicity of "Brain Surgeon," with say, a title like "Cephalic Surgeon." The term "Eye Surgeon" would be difficult to simulate or "borrow."

I am,

Yours truly,

C. Conor O'Malley.

6, THE CRESCENT,

GALWAY.

December 15, 1937.

\title{
OBITUARY
}

\section{A. HILL GRIFFITH}

WE regret to announce the death of Dr. Alexander Hill Griffith, which occurred at Woking on November 25, 1937, in his seventyninth year.

$\mathrm{He}$ was born in Aberdeen and was the seventh son of Charles Fox Griffith, J.P. He was educated at the Aberdeen Grammar School and University of Aberdeen and passed his final examinations for the degree of M.B., C.M., before he was twenty-one years of age. After his qualifying examination (April, 1879) and before he received his M.B. degree in April, 1880, he was appointed House Surgeon at the Manchester Royal Eye Hospital, a position which he held for nearly seven years. At that time little was done for the treatment of astigmatism and it was principally due to Griffith that adequate attention was given to this branch of refraction. Again during the time of his residence he was very interested in fields of vision and as a result of his investigations he wrote an excellent paper on this subject in the Manchester Medical Chronicle.

In 1883 he obtained the degree of M.D. In 1886 Griffith was appointed to the Honorary Surgical Staff of the hospital, first as assistant surgeon and three years later to the full staff. He was now in a position to pursue his clinical investigations and perfect his technique. This was supplemented by his love for histology. He was a keen microscopist and cut all his own sections. In 1896 he took the F.R.C.S.(Edin.). His contributions to our literature evidently attracted the attention of his contemporaries, for in 1897 he was awarded the Middlemore prize by the British Medical Association. 
In 1898 he wrote the section on diseases of the choroid and vitreous in Norris and Oliver's text book of ophthalmology. This was an excellent contribution on these subjects and amongst many interesting points he expressed views on the permeability of the suspensory ligament of the lens, a subject noted by him in a previous communication to the Ophthalmological Society.

In his chapter on choroidal disease he emphasized the importance of transillumination as an aid to the diagnosis of choroidal neoplasms.

In 1899 Griffith was appointed Honorary Ophthalmic Surgeon to The Manchester Royal Infirmary and later lecturer on ophthalmology to the University of Manchester.

He joined the Ophthalmological Society in 1885 , was on its committee from 1893 to 1896 and later was a Vice.President (1905 to 1908). For many years he was a member of the Manchester Medical Society and made several valuable contributions to it. For forty-three years he was a member of the British Medical Association was its secretary to the section of Ophthalmology at the annual meeting held in Manchester in 1902, and was VicePresident at the Belfast Meeting in 1909. He was one of the founders of the North of England Ophthalmological Society and was its first President.

On his appointment to the staff of the Manchester Royal Infirmary he was brought into contact with the students and it was soon apparent that his abilities as a teacher were great. His enthusiasm was immense and the way in which he investigated a case together with his sound reasoning were greatly appreciated. To one who was a student under him and subsequently his House Surgeon and colleague it is difficult to write about Griffith's work without the fear of exaggeration. Mention has been made of his teaching ability but when one was in a better position to appreciate his qualities as a clinician it became apparent that he was a master of his craft. He was a careful observer, his deductions were sound and convincing and he was a wizard with the ophthalmoscope. Griffith was an excellent operator. It was really delightful to watch his technique in such an operation as iridectomy for glaucoma for no anterior chamber seemed too shallow for him to enter with a broad keratome. Again, his cataract operations were beautifully executed and his originality is well illustrated by the novel manner in which he approached the corneo-sclera when trephining for glaucoma - a technique mentioned in Elliot's book on this subject.

As a colleague he was delightful to work with and he was always ready to help with his advice especially in difficult cases. Not only was he very much appreciated by his students and colleagues but was looked upon by his patients as a kind and helpful friend.

In addition to the large amount of hospital work he had a very extensive practice. He held the rank of Major R.A.M.C.(T.) and 
during the whole of the Great War gave valuable aid to the large number of wounded soldiers under treatment in Manchester.

He retired from practice in 1918 and went to live in Woking where he proceeded to enjoy his three great hobbies, singing, billiards and golf. He had always been attached to music and on his retirement he took singing lessons at regular intervals and proceeded to take part in musical competitions. How great was his delight when he showed one the marks he had gained in a singing competition and he took considerable interest in the criticisms of the adjudicators. He enjoyed a game of golf and at one time he was captain of the Manchester Golf Club (medical).

Early last year his health began to fail and a motor accident in the early summer may have caused further weakness. But there was still energy left, for he insisted on going up to London for a singing lesson a fortnight before he died. On his return from London he was so weak that he entered a nursing home and died as stated on November 25.

He was cremated at Woking and his ashes were scattered in St. Mary's Churchyard, Horsell, near Woking.

\section{NOTES}

Honour THE Royal Society of Medicine of Budapest, on the occasion of the centenary of foundation, has elected Sir John Parsons and Mr. Leslie Paton honorary members.

The Ophthalmological THE Annual Congress will be held in London Society of the on April 28, 29,30, 1938. The subject for

United Kingdom discussion is "The differential diagnosis of the causes of exophthalmos." Openers will be Mr. Foster Moore (Ophthalmology), Mr. T. E. Cawthorne (Ear, Nose and Throat), Dr. Russell-Brain (Medicine and Neurology).

Members who wish to take part in the discussion or to read papers should communicate with Mr. L. H. Savin, 7, Queen Street, Mayfair, W.1, if possible before February 28, 1938. Abstracts of papers, for circulation before the meeting, should be sent before March 27.

A visit will be arranged to White Oak Hospital, Swanley, by Mr. Arnold Sorsby, if a sufficient number of members send in their names before February 28. On the afternoon of April 30, the Post Office authorities have invited members of the Congress to visit their headquarters where the sorting offices, the Central Telegraph 